\title{
Human blood outgrowth endothelial cells improve islet survival and function when co-transplanted in a mouse model of diabetes
}

\author{
V. Coppens • Y. Heremans - G. Leuckx • K. Suenens • \\ D. Jacobs-Tulleneers-Thevissen $\cdot K$. Verdonck • \\ T. Lahoutte • A. Luttun • H. Heimberg • N. De Leu
}

Received: 13 June 2012 / Accepted: 20 September 2012 / Published online: 23 October 2012

(C) Springer-Verlag Berlin Heidelberg 2012

\begin{abstract}
Aims/hypothesis As current islet-transplantation protocols suffer from significant graft loss and dysfunction, strategies to sustain the long-term benefits of this therapy are required. Rapid and adequate oxygen and nutrient delivery by blood vessels improves islet engraftment and function. The present report evaluated a potentially beneficial effect of adult human blood outgrowth endothelial cells (BOEC) on islet graft vascularisation and function.

Methods Human BOEC, $5 \times 10^{5}$, were co-transplanted with a rat marginal-islet graft under the kidney capsule of hyperglycaemic NOD severe combined immunodeficiency (SCID) mice, and the effect on metabolic outcome was evaluated. Results Although vessel density remained unaffected, cotransplantation of islets with BOEC resulted in a significant
\end{abstract}

Electronic supplementary material The online version of this article (doi:10.1007/s00125-012-2754-3) contains peer-reviewed but unedited supplementary material, which is available to authorised users.

V. Coppens $\cdot$ Y. Heremans $\cdot$ G. Leuckx $\cdot$ K. Suenens $\cdot$

D. Jacobs-Tulleneers-Thevissen $\cdot H$. Heimberg $(\varangle) \cdot$

N. De Leu $(\triangle)$

Diabetes Research Center, Vrije Universiteit Brussel,

Laarbeeklaan 103,

1090 Brussels, Belgium

e-mail: Harry.Heimberg@vub.ac.be

e-mail: Nico.De.Leu@vub.ac.be

K. Verdonck $\cdot$ A. Luttun

Department of Cardiovascular Sciences,

Center for Molecular and Vascular Biology, KU Leuven,

Leuven, Belgium

T. Lahoutte

Laboratory for In Vivo Cellular and Molecular Imaging,

Vrije Universiteit Brussel,

Brussels, Belgium and specific improvement of glycaemia and increased plasma C-peptide. Moreover, in contrast to control mice, BOEC recipients displayed reduced beta cell death and increases in body weight, beta cell proliferation and graft-vessel and beta cell volume. In vivo cell tracing demonstrated that BOEC remain at the site of transplantation and do not expand. The potential clinical applicability was underscored by the observed metabolic benefit of co-transplanting islets with BOEC derived from a type 1 diabetes patient.

Conclusions/interpretation The present data support the use of autologous BOEC in translational studies that aim to improve current islet-transplantation protocols for the treatment of brittle type 1 diabetes.

Keywords Beta cell · Blood outgrowth endothelial cells · Diabetes $\cdot$ Islet transplantation

\begin{tabular}{|c|c|}
\hline \multicolumn{2}{|c|}{ Abbreviations } \\
\hline ALX & Alloxan monohydrate \\
\hline BLI & Bioluminescence imaging \\
\hline BOEC & Blood outgrowth endothelial cells \\
\hline BOEC-luc & $\begin{array}{l}\text { BOEC transduced with the luciferase } \\
\text { reporter gene }\end{array}$ \\
\hline EPC & Endothelial progenitor cells \\
\hline FWO & Research Foundation-Flanders \\
\hline HUVEC & Human umbilical vein endothelial cells \\
\hline Islet $^{\mathrm{BOEC}}$ & $\begin{array}{l}\text { Engrafted with islets in combination with } \\
\text { BOEC }\end{array}$ \\
\hline Islet $^{\mathrm{Ctr}}$ & Engrafted with islets alone \\
\hline Islet $^{\text {HUVEC }}$ & $\begin{array}{l}\text { Engrafted with islets in combination with } \\
\text { HUVEC }\end{array}$ \\
\hline Islet $^{\mathrm{T} 1 \mathrm{DBOEC}}$ & $\begin{array}{l}\text { Engrafted with islets in combination with } \\
\text { BOEC derived from a type } 1 \text { diabetic patient }\end{array}$ \\
\hline LE & Lycopersicon esculentum \\
\hline
\end{tabular}




$\begin{array}{ll}\text { MOI } & \text { Multiplicity of infection } \\ \text { NBF } & \text { Neutral-buffered formalin } \\ \text { PTx } & \text { Post-transplantation } \\ \text { SCID } & \text { Severe combined immunodeficiency }\end{array}$

\section{Introduction}

Islet transplantation is a promising therapy for patients with type 1 diabetes mellitus. Despite the recently reported improvement in metabolic outcome compared with the original Edmonton protocol [1], only $40-50 \%$ of patients remain insulin independent 5 years after transplantation $[2,3]$. Although the mechanism of graft failure remains elusive, more than $50 \%$ of grafted islets are destroyed during the first few days after transplantation [4, 5]. To compensate for this early loss, an excessively high number of donor islet cells need to be transplanted [6], further depleting the already scarce pool of donor tissue. Therefore, strategies that preserve early graft function and survival are needed, reducing the required number of islets per recipient. When cotransplanted, rat aortic endothelial cells have been shown to support beta cell function and/or survival [7]. Human cord-blood-derived endothelial progenitor cells (EPC) are beneficial to porcine islet graft transplantation via rapid graft revascularisation [8]. Nevertheless, the possibility of using adult human endothelial cells derived from the diabetic islet recipient has not yet been examined.

Human BOEC are a late outgrowing subtype of EPC [9] able to incorporate into newly forming vessels and provide trophic support to the host vasculature, as demonstrated in various models of tissue injury $[10,11]$. Furthermore, the minimal invasiveness to procure them from peripheral blood favours their use in autologous transplantation protocols.

We hypothesised that co-transplantation of human BOEC might improve islet engraftment in diabetic mice, ultimately resulting in amelioration of glycometabolic control.

\section{Methods}

Animals Male NOD severe combined immunodeficiency (SCID) mice, 9 weeks old, were obtained from Charles River Laboratories (L'Arbresle, Cedex, France) and housed alone or in pairs. The Principles of Laboratory Animal Care (NIH publication no. 85-23, revised 1985) as well as specific national laws were followed. In addition, the experimental plan was approved by the Ethical Committee for Animal Use of the Vrije Universiteit Brussel (VUB). For the induction of hyperglycaemia, the mice were injected i.v. with alloxan monohydrate (ALX) (Sigma-Aldrich, St Louis, $\mathrm{MO}$, USA) at a concentration of $50 \mathrm{mg} / \mathrm{kg}$ body weight and only used for experiments when, at 2 days after ALX injection, $2 \mathrm{~h}$ fasting blood glucose levels had reached at least $19.5 \mathrm{mmol} / \mathrm{l}$.

Islet isolation and culture As human beta cells were not systematically available for preclinical research projects and rat islets were readily available, a model of rat islet transplantation was adopted. Islets were isolated as previously described [12] from 6- to 10-week-old male Wistar rats (Janvier, Le Genest St Isle, France), weighing 250-300 g. After isolation, islets were cultured for 2 days in Ham's F10, supplemented with $2 \%$ (vol./vol.) FCS, 0.5\% (wt/vol.) BSA, $100 \mathrm{U} / \mathrm{ml}$ penicillin and $171.9 \mu \mathrm{mol} / \mathrm{l}$ streptomycin. At $1 \mathrm{~h}$ before transplantation, islets were washed twice and resuspended in PBS; only morphologically determined mediumsized islets $(150-250 \mu \mathrm{m})$ were used for transplantation after being hand-picked by an independent investigator who was unaware of the experimental conditions.

Cell derivation and culture HUVEC were cultured according to the manufacturer's instructions (Lonza, Verviers, Belgium). BOEC isolation and characterisation were performed as described previously [11]. Isolations were approved by the Ethical Committee of the University Hospital, Brussels. Participants gave informed consent. For further details of the methods, please refer to the Electronic supplementary material (ESM). Non-diabetic BOEC were isolated from the peripheral blood of a 31-year-old male healthy volunteer and diabetic BOEC were derived from a 19-year-old female donor with type 1 diabetes (overnight fasting blood glucose, $14.6 \mathrm{mmol} /$; $\mathrm{HbA}_{1 \mathrm{c}}, 11.1 \%$ [98 mmol/mol]). Isolated BOEC were cultured and frozen in liquid nitrogen when they reached passage six. To allow in vivo tracing, BOEC were transduced at multiplicity of infection (MOI) 100 with a lentivirus encoding luciferase under control of the $P G K$ promoter (at MOI 100, transduction efficiency with an enhanced green fluorescent protein (eGFP)encoding lentivirus was close to $100 \%$, as determined by FACS; data not shown), amplified until passage six and frozen in liquid nitrogen. At $1 \mathrm{~h}$ before transplantation, cells were thawed and resuspended in PBS. For each recipient mouse, $5 \times$ $10^{5}$ BOEC or HUVEC were mixed with islets. The islets or islet-BOEC/HUVEC mixture were centrifuged and washed once in $0.2 \mathrm{ml}$ transplantation medium (BioWhittaker, Lonza) supplemented with $2 \%$ male NOD SCID serum (Charles River Laboratories).

Transplantation and tissue harvest Mice were sedated using $10 \mu \mathrm{l} / \mathrm{g}$ body weight of $10 \mathrm{mg} / \mathrm{ml}$ ketamine $+0.1 \%$ (vol./vol.) xylazine, dissolved in physiological $\mathrm{NaCl}$ solution $(0.9 \%$; $154 \mathrm{mmol} / \mathrm{l})$. Tail-tip blood, $6 \mu \mathrm{l}$, from the recipient mouse was added to the islet/cell pellet, stirred gently and left to clot for $4 \mathrm{~min}$. The graft-containing blood clot was then inserted under the left kidney capsule. Tail-vein glycaemia was 
measured between 10:00 hours and 12:00 hours, following $2 \mathrm{~h}$ of fasting. For plasma C-peptide measurement, $0.25 \mathrm{ml}$ blood was collected from the tail vein in tubes containing Na-EDTA (2.2 $\mathrm{mg} / \mathrm{ml}$ blood) and aprotinin $(0.14 \mathrm{mg} / \mathrm{ml}$ blood). The samples were put on ice immediately after harvest and centrifuged for $15 \mathrm{~min}$ at $800 \mathrm{~g}$ at $4^{\circ} \mathrm{C}$. A $0.1 \mathrm{ml}$ volume of plasma was collected per sample and subjected to RIA for C-peptide (Linco Research, St Charles, Missouri, USA). At 16 and $2 \mathrm{~h}$ before they were killed, animals were injected i.p. with $10 \mathrm{mg} / \mathrm{kg}$ body weight BrdU (Sigma-Aldrich). At $10 \mathrm{~min}$ after i.v. injection of biotinylated Lycopersicon esculentum (LE) lectin (Vector Laboratories, Burlingame, CA, USA), animals were killed by cervical dislocation; this was followed by wholebody perfusion with PBS and subsequently $10 \%$ (vol./vol.) neutral-buffered formalin (NBF) via catheterisation of the left heart ventricle. The pancreases were harvested and processed for quantification of the residual insulin content by RIA [13].

Quantification of beta cell proliferation and death, vessel/islet ratio, vessel density, beta cell and blood vessel volume The transplanted left kidneys were fixed overnight at $4^{\circ} \mathrm{C}$ in $\mathrm{NBF}$, embedded in paraffin and the total graft area was cut into $4 \mu \mathrm{m}$ sections. Insulin was detected using a guinea pig anti-insulin antibody (1/3,000; gift of C. van Schravendijk, Diabetes Research Center, Vrije Universiteit Brussel, Brussels, Belgium). The biotinylated LE was visualised with Alexa-fluor-555-conjugated streptavidin (1/500; Invitrogen, Carlsbad, CA, USA). Human endothelial cells were detected via binding with FITC-labelled Ulex europaeus agglutinin (UEA) lectin (1/50, Sigma-Aldrich). Proliferating cells were detected by BrdU staining with a mouse monoclonal antibody (MP Biomedicals, Illkirch, France), requiring enzymemediated antigen retrieval with $0.5 \mathrm{mg} / \mathrm{ml}$ protease (SigmaAldrich). Secondary antibodies were Cy2- or Cy3-labelled $\mathrm{F}\left(\mathrm{ab}^{\prime}\right)_{2}$ fragments (Jackson Immunoresearch, Newmarket, Suffolk, UK), used at $1 / 100$ or $1 / 500$, respectively. TUNEL-positive cells were detected according to the manufacturer's recommendations (In Situ Cell Death Detection Kit, Roche Applied Science, Vilvoorde, Belgium). For quantification of the beta cell and blood vessel volumes, images were captured using a Nikon Eclipse TE2000-E microscope using a $\times 40$ magnification objective and the large image-capture feature so that the entire graft area of each section could be pictured at once. Insulin ${ }^{+}$areas and lectin $^{+}$areas within the endocrine compartment were measured semi-automatically by ImageJ software on $20 \%$ (i.e. every fifth section) of the total graft. Volumes were extrapolated from the respective sums of these areas, as described [14]. The vessel/islet ratio was calculated as (blood vessel volume/beta cell volume) $\times 100 \%$. Vessel density was calculated as the number of intra-islet vessels $/ \mathrm{mm}^{2}$. To determine the cell-death area, insulin-positive anuclear cell debris was manually selected and measured by ImageJ software. The cell-death area was calculated as the ratio of dead over total islet area $\times 100 \%$.

In vivo imaging Mice were sedated using $1 \%$ (vol./vol.) isoflurane, shaved and injected i.v. with $150 \mathrm{mg} / \mathrm{kg}$ body weight D-luciferin (Promega, Madison, WI, USA). Photon emission on the ventral and dorsal sides of the animal was measured for 10 min using a photo imager camera (Biospace, Paris, France). For signal comparison between the different animals and time points, an elliptical region of interest (ROI) was drawn over the area of the left kidney and the AUC was determined.

Data analysis All values shown are means \pm SEM. Twotailed unpaired $t$ tests or non-parametric Mann-Whitney tests were performed using GraphPad Prism version 5.0b for Mac (http://www.graphpad.com/). Results were considered significant when $p$ was less than 0.05 .

\section{Results}

Co-transplantation of a marginal-islet graft with BOEC reduces glycaemia in diabetic mice To investigate whether non-islet endothelial cells can positively influence an islet graft, a model of marginal-islet-mass transplantation was developed. Immunocompromised NOD SCID mice were made diabetic by i.v. injection of the beta cell-specific toxin ALX. Two days later, 150, 75 or 60 hand-picked rat islets were transplanted under the left kidney capsule. The $2 \mathrm{~h}$ fasting blood glucose was measured weekly until day 28 after transplantation. While engraftment of 150 and 75 islets resulted in stable normoglycaemia by day 7 following transplantation, mice transplanted with 60 islets remained hyperglycaemic during the entire follow-up period (ESM Fig. 1). The latter condition was adopted as a suboptimal islet mass for co-transplantation with non-islet endothelial cells.

In order to determine whether non-islet endothelial (progenitor) cells can improve islet graft function in vivo, $5 \times 10^{5}$ human BOEC or HUVEC were transplanted together with the marginal-islet mass. Changes in glycaemia and body weight gain were measured for 1 month after transplantation. While mice engrafted with islets alone $\left(\right.$ islet $^{\mathrm{Ctr}}$ ) or in combination with HUVEC (islet ${ }^{\mathrm{HUVEC}}$ ) returned to a state of severe hyperglycaemia 1 week after transplantation, mice engrafted with islets in combination with $\mathrm{BOEC}$ (islet ${ }^{\mathrm{BOEC}}$ ) showed a persistent decrease in glycaemia from day 4 onwards (Fig. 1a). The observed differences in glycaemia were statistically significant from day $14 \mathrm{PTx} ; p<0.0001$ (islet $^{\mathrm{Ctr}}$ [ $n=9] 30.30 \pm 1.05 \mathrm{mmol} / 1 \mathrm{vs}$ islet $^{\mathrm{HUVEC}}[n=6] 28.22 \pm$ $3.02 \mathrm{mmol} / 1$ vs islet $\left.^{\mathrm{BOEC}}[n=7] 12.18 \pm 3.27 \mathrm{mmol} / \mathrm{l}\right)$ until day 28 of the follow-up period (islet ${ }^{\mathrm{Ctr}}[n=9] 30.63 \pm$ $1.69 \mathrm{mmol} / 1$ vs islet ${ }^{\mathrm{HUVEC}}[n=6] 31.95 \pm 1.27 \mathrm{mmol} / 1$ vs 

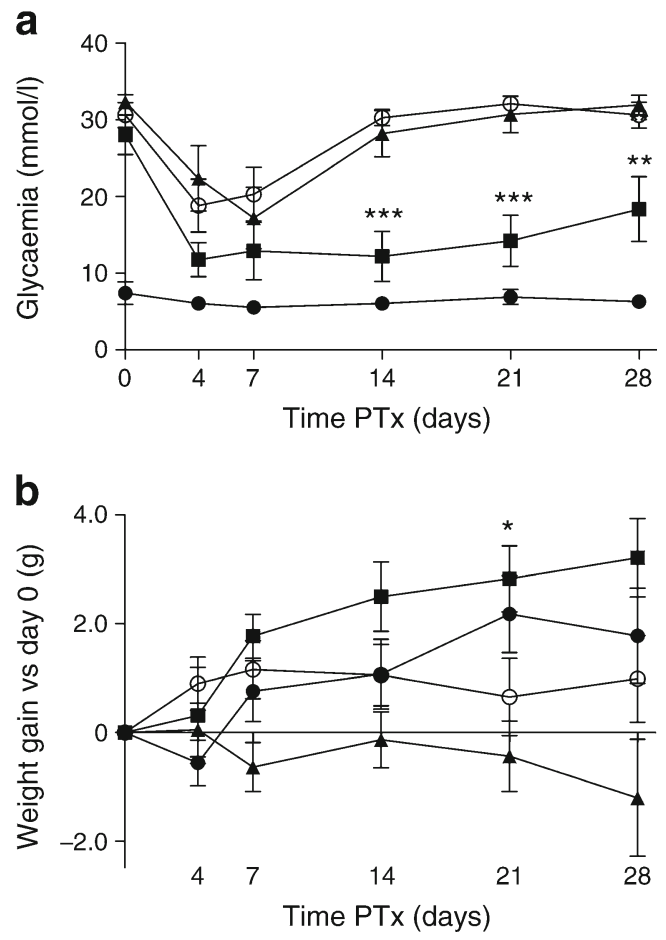

Fig. 1 BOEC enhance the metabolic outcome of marginal-islet-graft transplantation in diabetic mice. (a, b) On days 4, 7, 14, 21 and 28 PTx, $2 \mathrm{~h}$ fasting blood glucose level (a) and gain in body weight compared with weight on the day of transplantation (b) were measured in normoglycaemic mice ( $n=8$, black circles) and diabetic mice transplanted with a marginal-islet mass (islet ${ }^{\mathrm{Ctr}}, n=9$, white circles) or a marginalislet mass supplemented with $5 \times 10^{5}$ HUVEC (islet ${ }^{\mathrm{HUVEC}}, n=6$, triangles), or with $5 \times 10^{5} \mathrm{BOEC}$ (islet ${ }^{\mathrm{BOEC}}, n=7$, squares). Two-tailed unpaired $t$ tests were used to compare islet ${ }^{\mathrm{Ctr}}$ vs islet ${ }^{\mathrm{BOEC}}$ mice. ${ }^{*} p<0.05$, ${ }^{* *} p<0.01$ and ${ }^{* * *} p<0.001$

islet $^{\mathrm{BOEC}}[n=7] 18.36 \pm 4.24 \mathrm{mmol} / \mathrm{l} ; p<0.01$; Fig. 1a). In contrast to diabetic islet ${ }^{\mathrm{Ctr}}$ or islet ${ }^{\mathrm{HUVEC}}$ mice, islet ${ }^{\mathrm{BOEC}}$ mice quickly regained normal body weight following transplantation, indicating overall better health status (Fig. 1b). Furthermore, the average $\mathrm{C}$-peptide level of the islet ${ }^{\mathrm{BOEC}}$ mice was fourfold higher than in islet ${ }^{\mathrm{Ctr}}$ and islet ${ }^{\mathrm{HUVEC}}(792 \pm 188 \mathrm{pmol} /$ 1 in islet ${ }^{\mathrm{BOEC}}[n=7], 191 \pm 42 \mathrm{pmol} / 1$ in islet ${ }^{\mathrm{Ctr}}[n=9]$ and $167 \pm$ $38 \mathrm{pmol} / 1$ in islet ${ }^{\text {HUVEC }}[n=6]$; Fig. 2a), explaining the observed difference in blood glucose. Day 28 blood glucose and C-peptide levels of normoglycaemic (NG) control animals were, respectively, $6.29 \pm 0.69 \mathrm{mmol} / 1$ and $876.10 \pm 213.60$ $\mathrm{pmol} / \mathrm{l}(n=8)$. As HUVEC did not improve the metabolic outcome of mice with marginal-islet grafts, this experimental condition was not further elaborated. The insulin content of the endogenous pancreas of ALX-treated mice remained below $4 \%$ of non-diabetic control mice (Fig. 2b), indicating that the graft was responsible for decreased glycaemia in islet $^{\mathrm{BOEC}}$. These data indicate that BOEC improve glycaemic control and result in increased plasma C-peptide without affecting pancreas insulin content in marginal-isletengrafted animals.
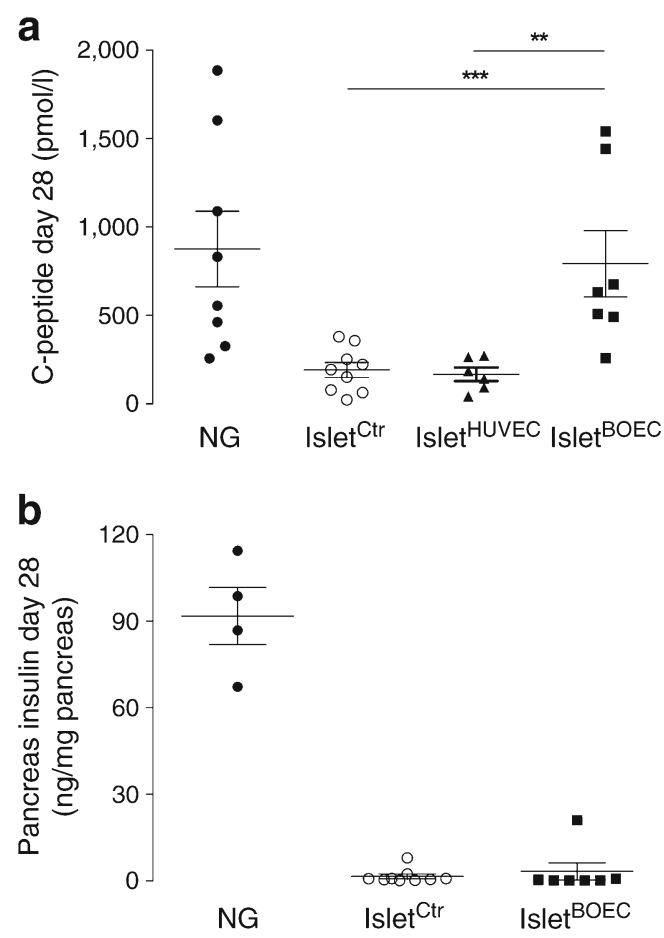

Fig. 2 BOEC co-engraftment results in increased plasma C-peptide without affecting endogenous pancreas insulin content. (a) Mean Cpeptide levels of normoglycaemic (black circles, $n=8$ ), islet ${ }^{\mathrm{Ctr}}$ (white circles, $n=9$ ), islet ${ }^{\mathrm{HUVEC}}$ (triangles, $n=6$ ) and islet ${ }^{\mathrm{BOEC}}$ (rectangles, $n=7$ ), mice at 28 days PTx. Mann-Whitney tests were used to compare islet ${ }^{\mathrm{Ctr}}$ and islet ${ }^{\mathrm{HUVEC}}$ vs islet ${ }^{\mathrm{BOEC}}$ mice. ${ }^{* *} p<0.01$ and ${ }^{* * * *} p<0.001$. (b) Pancreas insulin content 28 days after transplantation of untreated normoglycaemic mice (closed circles, $n=4$ ), diabetic mice transplanted with 60 islets (white circles, $n=9$ ) and diabetic mice transplanted with 60 islets and $5 \times 10^{5}$ BOEC (rectangles, $n=7$ )

Increased beta cell and blood vessel volume in islet ${ }^{B O E C}$ grafts To elucidate the mechanism behind the observed improvement of metabolic control following co-transplantation of islets and BOEC, kidneys were retrieved from islet ${ }^{\mathrm{Ctr}}$ or islet $^{\mathrm{BOEC}}$ mice at day 4 or $28 \mathrm{PTx}$ for further analysis. Prior to killing, animals were injected i.v. with tomato lectin, which binds to functional blood vessels [15]. Following labelling of tissue sections with specific antibodies, the insulin ${ }^{+}$and lectin $^{+}$area of $20 \%$ of the total graft was measured to allow calculation of vessel and beta cell volume (Fig. 3). The mean vessel volume of islet ${ }^{\mathrm{BOEC}}$ grafts compared with islet ${ }^{\mathrm{Ctr}}$ grafts was similar at day 4 PTx but had doubled by day 28 PTx (Fig. 3a, c). Graft-vessel density and vessel/islet ratio, calculated as the number of vessels per tissue area and the ratio of vessel to beta cell volume, respectively, did not differ in islet ${ }^{\mathrm{Ctr}}$ and islet ${ }^{\mathrm{BOEC}}$ at day 4 and 28 PTx (ESM Fig. 2). Although rare, some BOEC were observed in the vessel lining of functional blood vessels inside the islet graft (ESM Fig. 3).

While the mean beta cell volume of the islet ${ }^{\mathrm{Ctr}}$ grafts was $1.51 \pm 0.45 \times 10^{-2} \mathrm{~mm}^{3}(n=5)$ and $2.25 \pm 0.43 \times 10^{-2} \mathrm{~mm}^{3}$ $(n=7)$ at PTx days 4 and 28, respectively, two- and threefold 
Fig. 3 Beta cell and blood vessel volume of a marginalislet mass increase following BOEC co-transplantation. (a, b) Absolute blood vessel (a) and beta cell volumes (b) of grafts derived from mice transplanted with a marginal-islet mass alone (islet ${ }^{\mathrm{Ctr}}$, white circles, $n=5-7$ ), or in combination with $5 \times 10^{5}$ BOEC (islet ${ }^{\mathrm{BOEC}}$, black circles, $n=5-6)$. The arrowheads in (a) and (b) indicate the blood vessel and beta cell volume of the only islet ${ }^{\mathrm{BOEC}}$ mouse that was severely hyperglycaemic (blood glucose $>33.3 \mathrm{mmol} / \mathrm{l}$ ) on the day of harvest. (c) Immunostaining for insulin and detection of the LE, visualising functionally perfused blood vessels of islet ${ }^{\mathrm{Ctr}}$ and islet ${ }^{\mathrm{BOEC}}$-grafted kidney at day 28 PTx. Scale bar is $100 \mu \mathrm{m}$. The Mann-Whitney test was used to compare islet ${ }^{\mathrm{Ctr}}$ with islet ${ }^{\mathrm{BOEC}}$ mice in (a), and a two-tailed unpaired $t$ test was used to compare islet ${ }^{\mathrm{Ctr}}$ with islet $^{\mathrm{BOEC}}$ mice in (b). ${ }^{*} p<0.05$ and ${ }^{* * *} p<0.001$
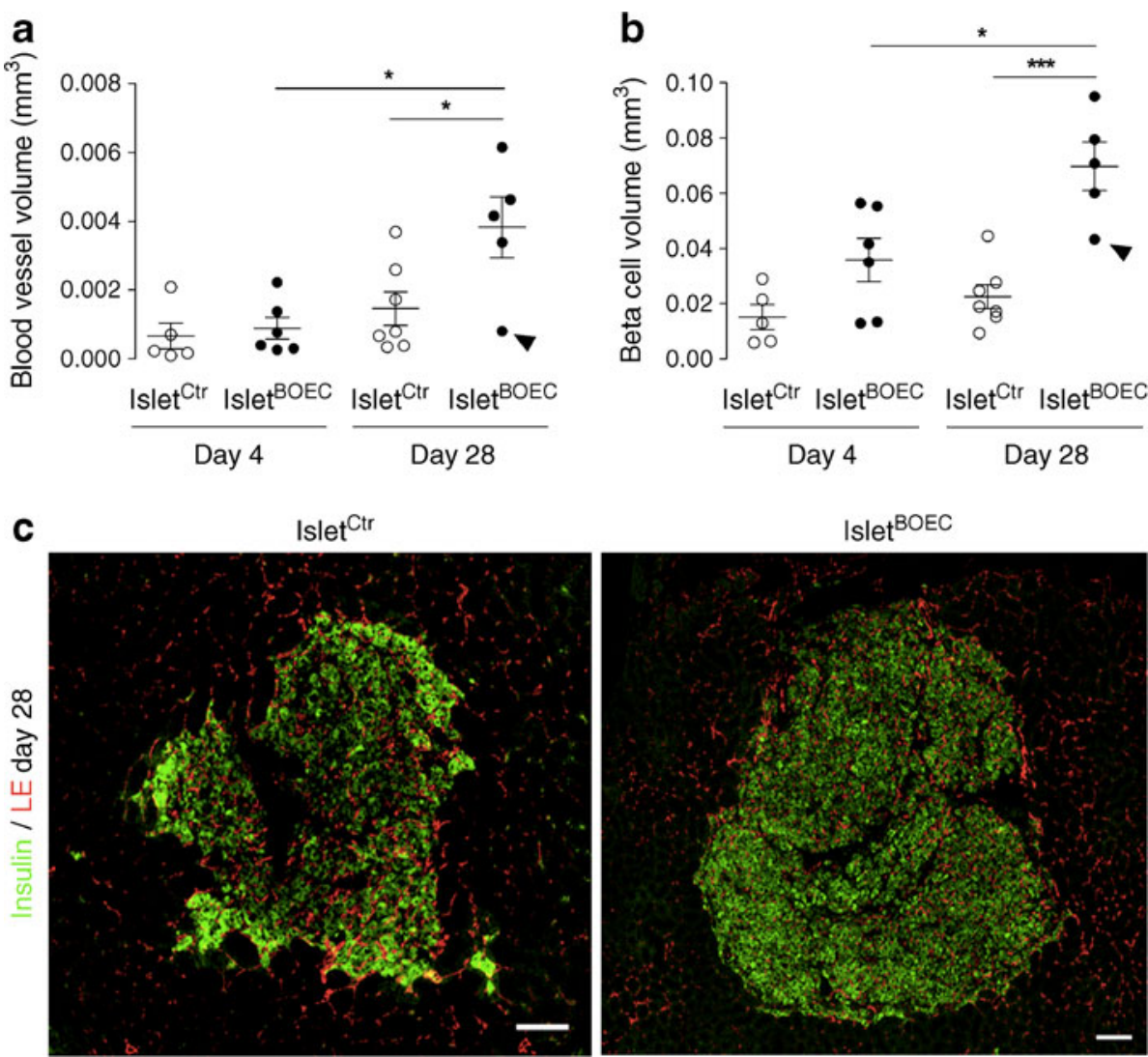

higher beta cell volumes were found in islet ${ }^{\text {BOEC }}$ grafts at day $4\left(3.58 \pm 0.79 \times 10^{-2} \mathrm{~mm}^{3}[n=6]\right)$ and day $28(6.98 \pm$ $0.87 \times 10^{-2} \mathrm{~mm}^{3}[n=5]$ ) PTx, respectively (Fig. 3b, c). This difference in beta cell volume between islet ${ }^{\mathrm{Ctr}}$ and islet ${ }^{\mathrm{BOEC}}$ was significant at day 28 PTx $(p<0.01)$ but not at day 4 PTx. Co-transplantation of BOEC and islets thus caused a doubling in the volume of functional blood vessels and a threefold increase in beta cell volume by day 28 PTx.

Reduced death and increased proliferation of beta cells in islet $^{\text {BOEC }}$ grafts As the beta cell volume of islet ${ }^{\text {BOEC }}$ mice tended to be higher at day 4 PTx compared with islet ${ }^{\mathrm{Ctr}}$ mice and significantly increased between day 4 and day 28 PTx, cell death and proliferation of the grafted beta cells was investigated. To evaluate the effect of BOEC on beta cell survival, TUNEL staining was performed at day 4 PTx to detect DNA fragmentation as a hallmark of beta cell apoptosis. No significant difference was observed in beta cell apoptosis level between islet ${ }^{\mathrm{BOEC}}$ and islet ${ }^{\mathrm{Ctr}}$, suggesting that BOEC do not protect against apoptosis-mediated beta cell death at day 4 PTx $\left(7.83 \pm 2.83 \%[n=6]\right.$ islet $^{\text {BOEC }}$ vs $4.35 \pm 3.65 \% \quad[n=4]$ islet $^{\mathrm{Ctr}} ; p>0.05$ ) (ESM Fig. 4). As TUNEL staining did not show beta cell apoptosis or necrosis earlier than day 4 PTx, we additionally screened for the presence of insulin ${ }^{+}$anuclear cell debris inside the engrafted islets of islet ${ }^{\mathrm{Ctr}}$ and islet ${ }^{\mathrm{BOEC}}$ mice, likely representing areas of cell death caused by apoptosis or necrosis before day 4
PTx. A significant increase in the cell-death area was observed in grafts of islet ${ }^{\mathrm{Ctr}}$ mice compared with islet ${ }^{\mathrm{BOEC}}$ grafts (islet $^{\mathrm{Ctr}}[n=5] 10.82 \pm 5.37 \%$; vs islet ${ }^{\mathrm{BOEC}}[n=6]$ $0.93 \pm 0.54 \%$; $p<0.05$; Fig. $4 \mathrm{a}, \mathrm{b})$. Moreover, large intraislet erythrocyte lakes, a consequence of end-stage islet cell death [5], were predominantly present in islet ${ }^{\mathrm{Ctr}}$ grafts (Fig. 4d, ESM Fig. 5). These data suggest that BOEC prevent beta cell death immediately after transplantation.

To evaluate the effect of BOEC on beta cell proliferation, islet $^{\mathrm{Ctr}}$ and islet ${ }^{\mathrm{BOEC}}$ were injected i.p. with the thymidine analogue BrdU at 16 and $2 \mathrm{~h}$ before the animals were killed. Grafts were harvested at day 4 and 7 PTx, immunostained for insulin and BrdU and double-positive cells were quantified. Beta cell proliferation was similar under all conditions at day 4 PTx, but had almost doubled in the grafts of islet $^{\mathrm{BOEC}}$ vs islet ${ }^{\mathrm{Ctr}}$ mice at day $7 \mathrm{PTx}(7.87 \pm 0.61 \%[n=4]$ vs $4.64 \pm 0.44 \%[n=7] ; p<0.05$ ) (Fig. 4c, d). These data suggest that the increase of beta cell volume between day 4 and 28 PTx in islet ${ }^{\mathrm{BOEC}}$ grafts was, at least partly, attributable to an increase in beta cell proliferation.

$B O E C$ remain at the transplantation site $\mathrm{BOEC}$ were transduced with the luciferase reporter gene (BOEC-luc), allowing in vivo tracing of the grafted cells by bioluminescence imaging (BLI). Non-transduced BOEC (serving as a nonluminescent control) and BOEC-luc were transplanted in diabetic mice and imaged at either the ventral or dorsal side 
a
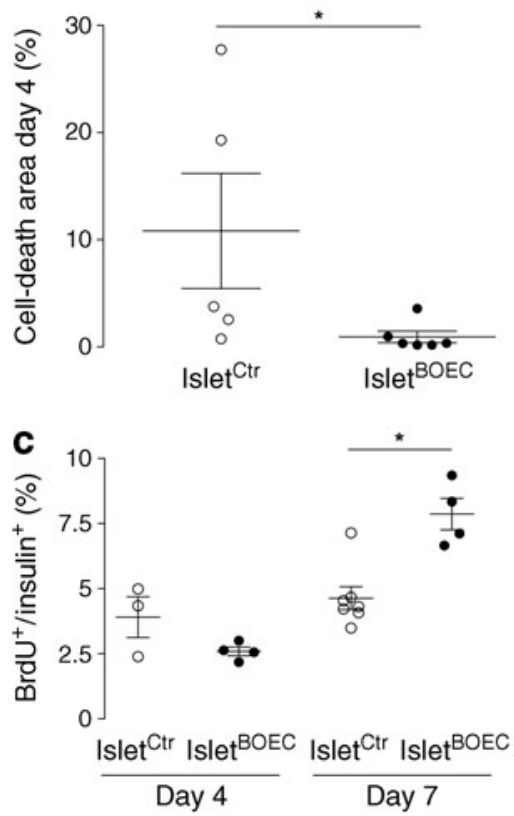

b

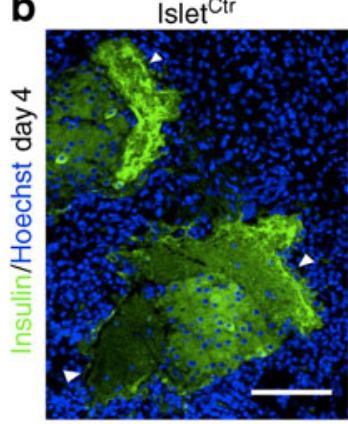

d

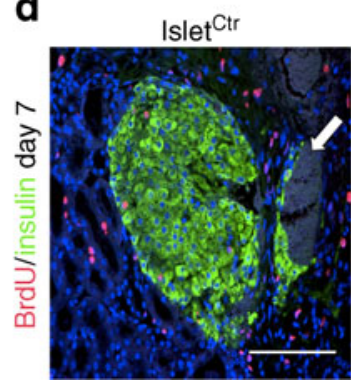

Islet ${ }^{\mathrm{BOEC}}$
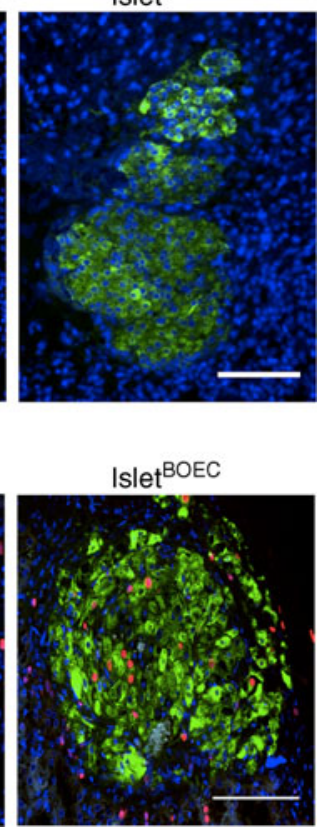

Fig. 4 BOEC protect against early beta cell death and promote beta cell proliferation after transplantation. (a) The percentage of islet celldeath area at PTx day 4 in islet ${ }^{\mathrm{Ctr}}$ (white circles, $n=5$ ) and islet ${ }^{\mathrm{BOEC}}$ (black circles, $n=6$ ) mice. (b) Immunostaining depicting insulin ${ }^{+}$, islet cell debris of islet ${ }^{\mathrm{Ctr}}$ - (arrowheads) and islet ${ }^{\mathrm{BOEC}}$-grafted kidneys. (c) The percentage of BrdU-positive $(\mathrm{BrdU})^{+}$beta cells at PTx days 4 and

of the animal at different times PTx. While a bioluminescent signal was not detected at any of the examined time points in islet ${ }^{\mathrm{BOEC}}$ mice or on the ventral side of islet ${ }^{\mathrm{BOEC}-\text { luc }}$ mice, a strong signal was emitted from the dorsal transplantation region of islet ${ }^{\mathrm{BOEC}-\mathrm{luc}}$ mice on day 1 PTx (Fig. 5a, b). This signal decreased by $90 \%$ on day 4 PTx and disappeared by day 14 PTx (Fig. 5a, b). After 1 week, mice were killed after i.v. injection of luciferin to allow ex vivo imaging of the organs. In contrast to a weak signal remaining in the transplanted left kidney, no signal could be detected in any of the other organs examined (Fig. 5c). Thus, BOEC do not survive for extended periods after transplantation nor do they significantly migrate from the transplantation site, making them safe for use in a clinical setting.

BOEC isolated from a type 1 diabetic patient improve islet graft function To enable autologous co-transplantation of BOEC with donor islets in a clinical setting, BOEC generated from patients with type 1 diabetes who will receive an islet graft, need to support a similar beneficial effect on the function of co-grafted islets as BOEC isolated from healthy individuals. A volume of $5 \times 10^{5}$ BOEC derived from a type 1 diabetes patient was transplanted together with 60 rat islets under the kidney capsule of diabetic NOD SCID (islet $^{\text {T1DBOEC }}$ ) mice. The $2 \mathrm{~h}$ fasting glycaemia and body weight were recorded up to 28 days after transplantation. At
7 in islet ${ }^{\mathrm{Ctr}}$ (white circles, $n=3-7$ ) and islet ${ }^{\mathrm{BOEC}}$ (black circles, $n=4$ ) mice. A Mann-Whitney test was used to compare islet ${ }^{\mathrm{Ctr}}$ with islet ${ }^{\mathrm{BOEC}}$ mice. ${ }^{*} p<0.05$. (d) Immunostaining for insulin and $\mathrm{BrdU}$ in islet ${ }^{\mathrm{Ctr}}$ - and islet ${ }^{\mathrm{BOEC}}$-grafted kidneys. Note the presence of an erythrocyte lake (arrow) in islet ${ }^{\mathrm{Ctr}}$-grafted kidney. Scale bar is $100 \mu \mathrm{m}$

day 28 PTx, blood was collected for quantification of the plasma C-peptide content. During the follow-up period, mice co-transplanted with type 1 diabetic BOEC displayed metabolic control similar to that of mice co-transplanted with control BOEC (Fig. 6). As a consequence, BOEC isolated from patients with type 1 diabetes are potential candidates for autologous transplantation to improve the metabolic outcome of co-engrafted donor islets.

\section{Discussion}

Early graft failure prevents long-term glyco-metabolic control in recipient type 1 diabetic patients [4, 5]. In addition, islet transplantation requires the use of multiple donors per recipient while donor organs are scarce. Therefore, strategies that improve the outcome of current transplantation protocols are urgently needed.

Previous reports have shown that endothelial (progenitor) cells of different origin can improve transplanted beta cell survival and function $[7,8,16]$. Nevertheless, in contrast to these studies, which evaluated the effect of non-human and/or human cord-blood-derived cells, the present study pioneers co-transplantation of adult human peripheral BOEC with a marginal-islet graft and reports a significant BOEC-specific increase in plasma $\mathrm{C}$-peptide levels and improvement in blood 
a

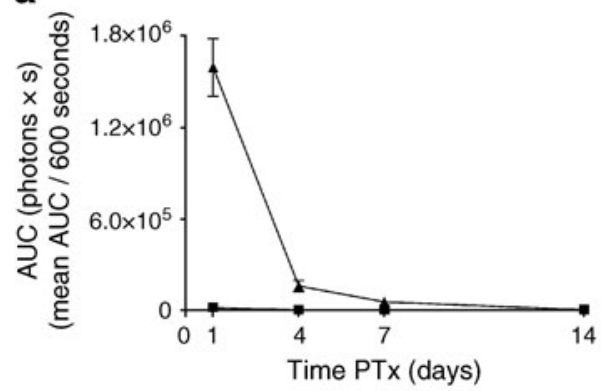

b

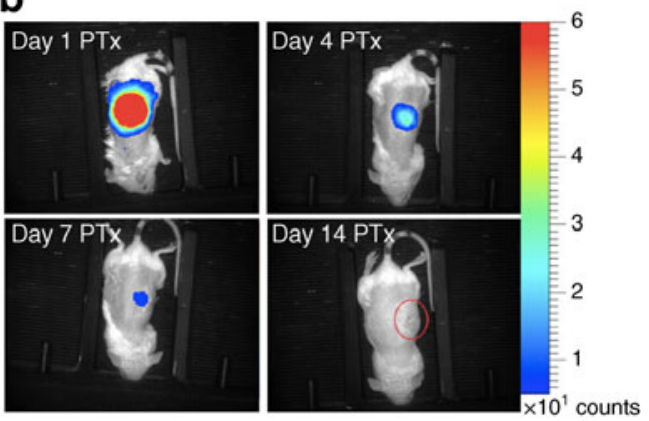

C

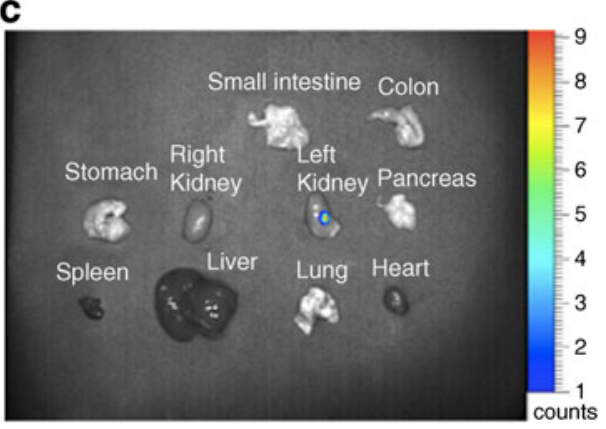

Fig. 5 BLI reveals that BOEC remain in situ and do not form tumours on transplantation. (a) Follow-up for 14 days of the bioluminescent signal emitted from mice transplanted with a marginal-islet mass and $5 \times 10^{5}$ non-transduced BOEC (islet ${ }^{\mathrm{BOEC}}$, squares, $n=3$ ) or $5 \times 10^{5}$ luciferase-transduced BOEC (islet ${ }^{\mathrm{BOEC}-l u c}$, triangles, $n=3$ ). (b) Images of islet ${ }^{\text {BOEC-luc }}$ mouse with the highest day 1 PTx signal of the imaged time points (PTx days 1, 4, 7 and 14). Circle indicates scar area over transplantation area, coinciding with luciferase signal at earlier time points. (c) Ex vivo imaging of organs, harvested on day 21 PTx from the same islet ${ }^{\mathrm{BOEC}-l u c}$ mouse as depicted in (b)

glucose control. As the insulin content of the endogenous diabetic pancreas did not change, an indirect effect of BOEC on the endogenous beta cell mass can be ruled out. Moreover, at day $28 \mathrm{PTx}$, a threefold increase in graft beta cell volume was observed in islet ${ }^{\mathrm{BOEC}}$ mice, thereby further supporting the beneficial effect of BOEC on islet cell transplantation.

Interestingly, in islet ${ }^{\mathrm{BOEC}}$ mice, the trend towards an increase in beta cell volume was already apparent at day 4 PTx, likely reflecting a reduction in beta cell death before day 4 PTx. Islets of control mice showed an increased incidence of intra-islet insulin ${ }^{+}$cell debris and erythrocyte lakes, the latter as a consequence of end-stage beta cell death a

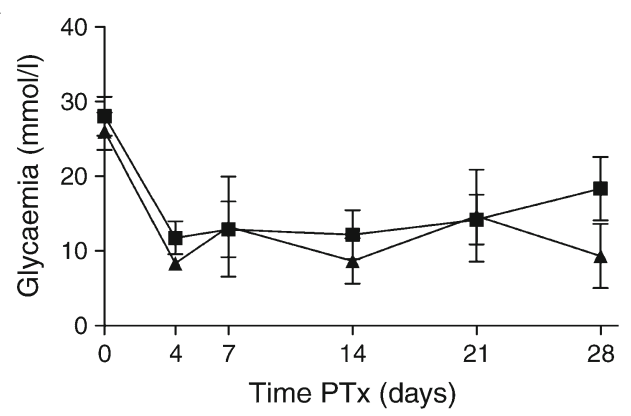

b

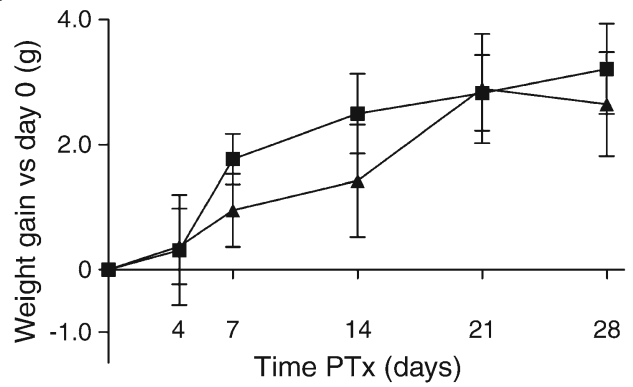

C

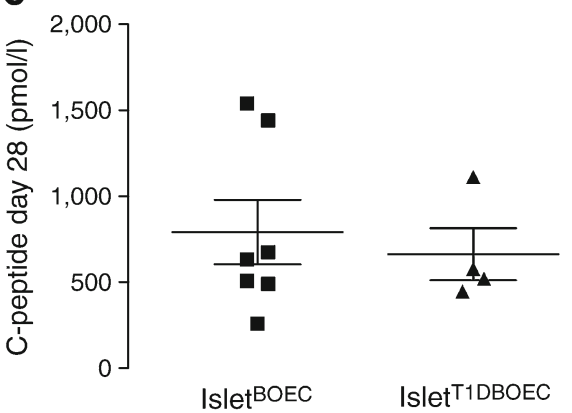

Fig. 6 BOEC derived from a type 1 diabetic patient provide a similar metabolic outcome as BOEC derived from healthy volunteers when co-transplanted with a marginal-islet mass. (a, b) One month follow-up of $2 \mathrm{~h}$ fasting blood glucose levels (a) and body weight gain compared with weight on the day of transplantation (b) of diabetic mice transplanted with a marginal-islet mass supplemented with $5 \times 10^{5}$ type 1 diabetic BOEC ( $n=4$ islet $^{\text {TIDBOEC }}$, triangles). Values were compared with and plotted against blood glucose and body weight data for diabetic mice that received a marginal-islet mass supplemented with $5 \times 10^{5}$ BOEC derived from a non-diabetic individual (as in Fig. 1, squares, $n=7$ ). (c) C-peptide levels of islet ${ }^{\mathrm{BOEC}}$ (squares, $n=7$ ) and islet $^{\text {T1DBOEC }}$ (triangles, $n=4$ ) mice at 28 days PTx

[5] with subsequent erythrocyte deposition. While the observed differences in intra-islet insulin ${ }^{+}$cell debris support an advantageous effect of BOEC on beta cell survival, the reduced prevalence of erythrocyte lakes in islet ${ }^{\mathrm{BOEC}}$ mice may result from BOEC-mediated prevention of erythrocyte lake formation and/or clearance of erythrocytes from intraislet cell-death areas. Moreover, whereas the use of a blood clot facilitates delivery of islet cells under the kidney capsule [17], it cannot be excluded that this method increases the incidence of erythrocyte lake formation or that BOEC 
exert a beneficial effect on the deleterious consequences of instant blood-mediated inflammatory reaction, initially described after intra-portal islet transplantation [18] and potentially stimulated by the use of a blood clot in the current model.

Besides differences in beta cell death, a significant rise in beta cell volume was observed from day 4 to day $28 \mathrm{PTx}$ in islet ${ }^{\mathrm{BOEC}}$ mice, at least partly as a result of an increase in beta cell proliferation rate at day 7 PTx. Interestingly, while the proliferative capacity of beta cells has been questioned for many years, recent lineage-tracing studies have revealed the remarkable capacity of adult beta cells to support beta cell mass maintenance and regeneration through replication [19-21]. Our data underscore the potential of beta cells to replicate in an islet-transplantation setting and are in line with a beneficial effect of co-transplantation of EPC on the replication rate of the engrafted beta cells [8]. Unlike Kang et al [8], the current report shows the effect of adult human outgrowth endothelial cells with autologous potential rather than the effect of cord-blood-derived EPC.

While increased proliferation of islet cells, when cotransplanted with human cord-blood-derived EPC, was associated with an increased graft-vessel density [8], the grafts of islet ${ }^{\mathrm{BOEC}}$ mice showed no such increase at either the early or the late stages following transplantation. Nonetheless, the absolute volume of functionally perfused vessels increased more than twofold at day 28 PTx in islet ${ }^{\mathrm{BOEC}}$ compared with islet ${ }^{\mathrm{Ctr}}$ mice, thereby indicating that vessel volume proportionally increased with the rise in beta cell volume. Whether this increase is causally related to and solely originates from the expanding beta cell mass or from additional BOEC-derived signalling remains to be determined. Of note, while some BOEC could be visualised inside the vessel wall of the islet grafts, its rarity precludes a major contribution of this phenomenon to the absolute increase in blood vessel volume. Based on the observation that vessel density was comparable between islet ${ }^{\mathrm{Ctr}}$ and islet ${ }^{\mathrm{BOEC}}$ mice and on the rarity of BOEC that integrated in islet blood vessels, the positive influence of BOEC on islet transplantation likely results from a direct or indirect protective/ trophic effect on the engrafted beta cells, rather than from their angiogenic potential. Even though others reported that endothelial cells can directly stimulate beta cell proliferation [22], future work will address this issue by determining whether BOEC can directly promote beta cell survival and proliferation in vitro. If this is the case, a search for the factors involved will be initiated. Compared with HUVEC, BOEC produce high levels of the angiogenic factors vascular endothelial growth factor (VEGF), placental growth factor (PlGF), platelet-derived growth factor $\beta$ polypeptide (PDGF-B), angiopoietin-2 (ANG2) and matrix metalloproteinases (MMPs: MMP-1, -9 and -14), as well as hepatocyte growth factor (HGF) [11], the last of which has previously been identified as important for both endothelial and beta cell proliferation [23-25]. It is tempting to speculate that at least some of these factors orchestrate the beneficial effect of BOEC and thereby explain the observed differences between BOEC and HUVEC on islet transplantation.

Transduction with luciferase-producing lentivirus enabled us to monitor the fate of the transplanted BOEC. While a bioluminescent signal was still detected in the explanted kidney at day $21 \mathrm{PTx}$, the in vivo luciferase signal was decreased to $10 \%$ of the level of the starting signal at day 4 PTx. Whether this loss of signal is due to clearance of BOEC by the remaining innate immunity in recipient NOD SCID mice or reflects the natural time course of BOEC survival when engrafted under the kidney capsule remains to be evaluated. Notably, as the positive metabolic effect of BOEC lasted up to at least 1 month PTx, it is likely that: (1) BOEC initiate a downstream cascade of events that support a long-term beneficial effect on co-transplanted islets; and/or (2) only a limited amount of BOEC are required to positively influence islet graft function and/or survival. As the bioluminescent signal gradually decreased and no extra-renal signal could be detected during the entire follow-up period, BOEC do not appear to bear tumourigenic and/or metastatic potential, a critical feature for clinical transplantation. Nonetheless, long-term follow-up is essential to further support this statement.

Finally, the clinical applicability of the present approach was underscored by providing evidence that BOEC derived from a type 1 diabetic patient bear the same potential to reverse hyperglycaemia as their non-diabetic counterparts. This finding allows autologous use of BOEC, bypassing recipient immune reaction against allogeneic graftsupporting cells. As some endothelial cell types, such as liver sinusoidal endothelial cells [26], appear to possess antigen-presenting capacities that result in antigen-specific $\mathrm{T}$ cell tolerance, a feature which has also been attributed to mesenchymal stem cells (MSC) [27], the question of whether BOEC display a similar tolerogenic potential or, in contrast, enhance the immunogenicity of the islet cell graft merits further investigation. Furthermore, the effect of BOEC on human instead of rodent beta cell grafts, at the levels both of metabolic and immunogenic outcome, needs to be addressed in future experiments.

In conclusion, BOEC improve the metabolic outcome of experimental rat islet transplantation, remain located at the engraftment site and do not clonally expand when grafted. BOEC harvested from a type 1 diabetic patient are equally functional and might represent an attractive candidate to improve the success of clinical islet transplantation.

Acknowledgements Special thanks to A. Demarré, K. Sterck, V. Laurysens, M. Jacobs, G. Stangé, L. Baeyens, J. De Jonge S. Devos and C. Peleman, from the Vrije Universiteit Brussel, and B. Hendrickx, from KU Leuven, for technical advice and assistance. 
Funding Financial support was from the Institute for the Promotion of Innovation by Science and Technology in Flanders (IWT) (V. Coppens and H. Heimberg), the Research Foundation-Flanders (FWO) (H. Heimberg, N. De Leu and D. Jacobs-Tulleneers-Thevissen), the VUB Research Council (H. Heimberg), the European Union Sixth and Seventh Framework Program (H. Heimberg), the Belgian Federal Science Policy (H. Heimberg) and Programme Financing KU Leuven (PF/10/014; A. Luttun). T. Lahoutte is a senior clinical investigator of the FWO.

Contribution statement All authors designed methods and experiments. VC, GL, KS, DJTT, KV and YH carried out the experiments. $\mathrm{AL}, \mathrm{KV}$ and TL provided technical support and reagents. VC analysed the data. VC, YH, NDL and HH wrote the paper. All authors revised and approved the final manuscript.

Duality of interest The authors declare that there is no duality of interest associated with this manuscript.

\section{References}

1. Shapiro AM, Lakey JR, Ryan EA et al (2000) Islet transplantation in seven patients with type 1 diabetes mellitus using a glucocorticoidfree immunosuppressive regimen. N Engl J Med 343:230-238

2. Barton FB, Rickels MR, Alejandro R et al (2012) Improvement in outcomes of clinical islet transplantation: 1999-2010. Diabetes Care 35:1436-1445

3. Shapiro AM (2011) State of the art of clinical islet transplantation and novel protocols of immunosuppression. Curr Diab Rep 11:345-354

4. Davalli AM, Scaglia L, Zangen DH, Hollister J, Bonner-Weir S, Weir GC (1996) Vulnerability of islets in the immediate posttransplantation period. Dynamic changes in structure and function. Diabetes 45:1161-1167

5. Biarnes M, Montolio M, Nacher V, Raurell M, Soler J, Montanya E (2002) Beta-cell death and mass in syngeneically transplanted islets exposed to short- and long-term hyperglycemia. Diabetes 51:66-72

6. Keymeulen B, Gillard P, Mathieu C et al (2006) Correlation between beta cell mass and glycemic control in type 1 diabetic recipients of islet cell graft. Proc Natl Acad Sci USA 103:17444-17449

7. Song HJ, Xue WJ, Li Y et al (2010) Prolongation of islet graft survival using concomitant transplantation of islets and vascular endothelial cells in diabetic rats. Transplant Proc 42:2662-2665

8. Kang S, Park HS, Jo A et al (2012) Endothelial progenitor cell cotransplantation enhances islet engraftment by rapid revascularization. Diabetes 61:866-876

9. Yoder MC, Mead LE, Prater D et al (2007) Redefining endothelial progenitor cells via clonal analysis and hematopoietic stem/progenitor cell principals. Blood 109:1801-1809

10. Moubarik C, Guillet B, Youssef B et al (2011) Transplanted late outgrowth endothelial progenitor cells as cell therapy product for stroke. Stem Cell Rev 7:208-220
11. Hendrickx B, Verdonck K, van den Berge S et al (2010) Integration of blood outgrowth endothelial cells in dermal fibroblast sheets promotes full thickness wound healing. Stem Cells 28:1165-1177

12. Pipeleers DG, Pipeleers-Marichal M, Hannaert JC et al (1991) Transplantation of purified islet cells in diabetic rats. I. Standardization of islet cell grafts. Diabetes 40:908-919

13. Xu X, D'Hoker J, Stangé G et al (2008) Beta-cells can be generated from endogenous progenitors in injured adult mouse pancreas. Cell 132:197-207

14. Olerud J, Kanaykina N, Vasylovska S et al (2009) Neural crest stem cells increase beta cell proliferation and improve islet function in co-transplanted murine pancreatic islets. Diabetologia 52:2594 2601

15. McDonald DM, Choyke PL (2003) Imaging of angiogenesis: from microscope to clinic. Nat Med 9:713-725

16. Pan X, Xue W, Li Y, Feng X, Tian X, Ding C (2011) Islet graft survival and function: concomitant culture and transplantation with vascular endothelial cells in diabetic rats. Transplantation 92:12081214

17. Bogdani M, Suenens K, Bock T, Pipeleers-Marichal M, In't Veld P, Pipeleers D (2005) Growth and functional maturation of beta-cells in implants of endocrine cells purified from prenatal porcine pancreas. Diabetes 54:3387-3394

18. Moberg L, Johansson H, Lukinius A et al (2002) Production of tissue factor by pancreatic islet cells as a trigger of detrimental thrombotic reactions in clinical islet transplantation. Lancet 360:2039-2045

19. Dor Y, Brown J, Martinez OI, Melton DA (2004) Adult pancreatic beta-cells are formed by self-duplication rather than stem-cell differentiation. Nature 429:41-46

20. Nir T, Melton DA, Dor Y (2007) Recovery from diabetes in mice by beta cell regeneration. J Clin Invest 117:2553-2561

21. Teta M, Rankin M, Long S, Stein G, Kushner J (2007) Growth and regeneration of adult beta-cells does not involve specialized progenitors. Dev Cell 12:817-826

22. Nikolova G, Jabs N, Konstantinova I et al (2006) The vascular basement membrane: a niche for insulin gene expression and beta cell proliferation. Dev Cell 10:397-405

23. Bussolino F, Di Renzo MF, Ziche M et al (1992) Hepatocyte growth factor is a potent angiogenic factor which stimulates endothelial cell motility and growth. J Cell Biol 119:629-641

24. Johansson M, Mattsson G, Andersson A, Jansson L, Carlsson PO (2006) Islet endothelial cells and pancreatic beta-cell proliferation: studies in vitro and during pregnancy in adult rats. Endocrinology 147:2315-2324

25. Garcia-Ocaña A, Takane KK, Syed MA, Philbrick WM, Vasavada RC, Stewart AF (2000) Hepatocyte growth factor overexpression in the islet of transgenic mice increases beta cell proliferation, enhances islet mass, and induces mild hypoglycemia. J Biol Chem 275:1226-1232

26. Limmer A, Ohl J, Kurts C, Ljunggren HG, Reiss Y, Groettrup M, Momburg F, Arnold B, Knolle PA (2000) Efficient presentation of exogenous antigen by liver endothelial cells to CD8+ T cells results in antigen-specific T cell tolerance. Nat Med 6:1348-1354

27. Sotiropoulou PA, Papamichail M (2007) Immune properties of mesenchymal stem cells. Methods Mol Biol 407:225-243 